\title{
A SEGURANÇA QUE NÃO É PARA TODOS: DISCURSOS SOBRE VIOLÊNCIA E SEGURANÇA PÚBLICA
}

\author{
ANGELA CORRÊA FERREIRA BAALBAKI ${ }^{1}$ \\ FERNANDA MORAES D'OLIVO
}

Programa de Pós-Graduação em Letras - Instituto de Letras

Universidade do Estado do Rio de Janeiro

R. São Francisco Xavier, 524 - 20550-900 - Rio de Janeiro-RJ - Brasil

Faculdade de Filosofia, Ciências e Letras

Fundação Técnico-Educacional Souza Marques

Av. Ernani Cardoso, 335 -21310-310- Rio de Janeiro-RJ - Brasil

angelabaalbaki@hotmail.com ; fernanda.dolivo@gmail.com

\begin{abstract}
Resumo. Pautadas no dispositivo teórico da Análise do Discurso de perspectiva materialista, analisamos os recortes de dois materiais distintos cuja temática é a violência urbana. Esses recortes são constituídos por comentários publicados no portal de notícias G1 sobre a morte do menino Ryan, vítima de bala perdida, e por excertos do texto ECA do B, escrito por Eliane Brum e publicado no periódico on-line El País-Brasil, o qual se configura como uma paródia do Estatuto da criança e do adolescente (ECA). A partir da análise desses recortes, buscamos compreender como os sentidos sobre violência e segurança pública se significam e circulam no social, quando os sujeitos vítimas da violência urbana são jovens e crianças negras e pobres.
\end{abstract}

Palavras-chave: Análise do discurso materialista; violência urbana; segurança pública; denúncia; tensão social.

\begin{abstract}
Guided by the materialism-oriented theoretical background of Discourse Analysis, we have analyzed two different materials whose theme is the urban violence. Those clippings consist of comments posted at the G1 news portal on the death of the boy named Ryan, victim of a stray bullet, and excerpts of the text called ECA do B, written by Eliane Brum and published in the online newspaper El Pais-Brasil, which configured as a parody of the Child and Adolescent Statute (ECA - Estatuto da criança e do adolescente). Through the analysis of those clippings, we sought to understand how the renderings of violence and public security make sense and have their meanings circulating in the social space when the subject victims of urban violence are adolescents and black and poor children.
\end{abstract}

Keywords: Materialism-oriented Discourse Analysis; urban violence; public security; denouncement; social tension.

\footnotetext{
${ }^{1}$ Doutora em Letras (UFF). Professora no Departamento de Estudos da Linguagem e do Programa de PósGraduação em Letras do Instituto de Letras, Universidade do Estado do Rio de Janeiro (UERJ).

${ }^{2}$ Doutora em Linguística (Unicamp). Professora na Fundação Técnico-Educacional Souza Marques (RJ).
} 
A prática da violência, como toda ação muda o mundo, mas a mudança mais provável, é para um mundo mais violento.

Hannah Arendt

\section{Introdução}

O significante segurança acompanhado do adjetivo pública - segurança pública remete-nos a outro significante: violência. Em nossa sociedade, estamos cercados por dizeres que mostram e marcam a mazela da segurança pública ao enunciar tantos casos de violência publicizados pela mídia.

A palavra violência, porém, não apresenta o mesmo sentido, conforme podemos observar em diferentes enunciados (quais sejam: violência doméstica; violência armada; violência pública, etc.), assim como segurança também não significa o mesmo para todos os sujeitos. As palavras, conforme nos lembra Pêcheux (1975, p. 160), "mudam de sentido segundo as posições daqueles que as empregam, o que quer dizer que elas tomam seus sentidos em referência a essas posições”. Segundo Orlandi (2012, p. 212), a violência é causada pela segregação e distanciamento que configuram as relações sociais atuais em meio ao urbano e, desse modo, violência e segurança se significam de forma diferente para as diferentes classes sociais em nosso país.

Nosso gesto de análise dá-se em um "movimento pendular entre teoria e análise" (PETRI, 2013, p. 40), compreendido como uma proposta metodológica da Análise de Discurso que se caracteriza pela singularidade. Como ressalta Petri (2013), o movimento pendular "tem início no contato do analista com o seu objeto de análise" (p. 42). Em face desse movimento, nosso gesto analítico constituiu-se a partir de perguntas que, buscando deslocar sentidos, interrogam sobre o funcionamento de alguns comentários produzidos por leitores da notícia "Ryan foi vítima de bala perdida, diz delegado após perícia em favela" e publicados no Portal G1, em 30 de março de 2016, e do texto "ECA do B", escrito pela jornalista Eliane Brum e publicado em El País- Brasil, em 25 de setembro de 2015. A partir desse material de análise, voltamos o nosso olhar para o discurso sobre violência e segurança pública que diz respeito às crianças e aos adolescentes vítimas da violência. Falar da violência contra crianças no Brasil nos leva às seguintes perguntas: que sentidos de criança e adolescente seriam produzidos nessas textualizações? Quais discursos ecoam (n)esses materiais? Como eles significam dizeres sobre violência, segurança pública? O que pode ser lido, além do que é dito, nesses comentários e no texto ECA do $B$ de Eliane Brum?

Esses questionamentos orientarão nossas análises sustentadas no aparato teóricometodológico da Análise de Discurso, o qual busca, por meio de uma análise não subjetiva da subjetividade (PÊCHEUX, 1975/1988), compreender os jogos e efeitos de sentidos produzidos nas discursividades que circulam no social. E é no jogo entre a dicotomia formada pelos significantes violência (urbana)/ segurança (pública) que nossas análises se desenvolverão, levando em conta a articulação do simbólico com o político que configuram as relações sociais dos/entre os sujeitos com o significante, com o espaço urbano, com a demanda de sentidos (ORLANDI, 1999).

Para responder às nossas inquietações, movimentaremos, principalmente, os conceitos de pré-construído, silenciamento e juridismo. Em relação ao nosso dispositivo analítico, as demais noções mobilizadas serão apresentadas ao longo das análises, em 
batimento entre teoria e análise. Ressalta-se que objeto de análise não é algo pronto, precisa receber certos tratamentos da materialidade linguística que fornece pistas para a compreensão do modo de funcionamento do discurso, ou melhor, a partir de "vestígios" linguísticos, a análise do processo discursivo pode ser desenvolvida. Estes "vestígios" marcas identificáveis na superfície linguística que remetem à existência material da língua (PÊCHEUX, 1988) - não apresentam uma relação automática com o processo discursivo, ou seja, deve-se considerar o modo como tais marcas aparecem no discurso. Em nosso percurso analítico, observaremos advérbios, nomeações, entre outros. Comecemos com os recortes dos comentários produzidos a partir da notícia selecionada sobre a morte de Ryan e os resultados da investigação.

\section{A violência nos comentários}

Segundo Medeiros (2011), “o significante 'violência' faz parte da mídia nos anos 1990 e adentra a mídia no século XXI, sobretudo o significante "violência pública"” (p. 205). Notícias sobre acontecimentos violentos, assaltos, assassinatos que assolam, principalmente, os grandes centros urbanos são constantes na mídia, em seus diferentes suportes de divulgação (mídia radiofônica, impressa, televisiva e digital), o que, segundo Orlandi (1999), acentua o imaginário de violência nas cidades, "na medida em que investe nesse processo de significação ao invés de procurar rompê-lo" (op.cit., p.5).

Dos inúmeros casos de violência mostrados nos meios de comunicação, há histórias que se repetem: no Rio de Janeiro, há sempre notícias de balas perdidas que encontram corpos, principalmente, os dos moradores de favelas, entre esses, crianças e adolescentes pobres. Porém, algumas notícias parecem que recebem mais destaque, seja por quem foi baleado ou pelos protestos que tal violência gerou. Foi assim com o caso do garoto Ryan ${ }^{3}$.

Conforme apresentado em jornais online, Ryan, de apenas quatro anos, foi baleado enquanto brincava em frente à casa de seu avô no subúrbio do Rio de Janeiro. Foram muitas as especulações sobre a morte: havia a hipótese de vingança, já que o pai do menino era um traficante da região, preso há algum tempo. Porém, no decorrer das investigações, constatou-se que Ryan foi vítima de bala perdida, conforme nos dizem, pela mídia, os responsáveis pela investigação. Como já foi apresentado, constitui-se como corpus deste trabalho comentários que aparecem na notícia cuja manchete é "Ryan foi vítima de bala perdida, diz delegado após perícia em favela" ", publicada no Portal G1 em 30 de março de 2016. Especificamente, nesta notícia, o delegado responsável pelo caso apresenta o resultado das investigações, confirmando que Ryan foi vítima de bala perdida e não de um ato de vingança contra o seu pai, como era suspeitado anteriormente.

\footnotetext{
${ }^{3}$ Seguem alguns links de notícias sobre a morte do garoto Ryan e dos protestos decorrentes de tal fato: http://g1.globo.com/rio-de-janeiro/noticia/2016/03/volta-meu-filho-se-desespera-mae-de-menino-mortopor-bala-perdida-no-rio.html; http://g1.globo.com/rio-de-janeiro/noticia/2016/03/ryan-foi-vitima-de-balaperdida-diz-delegado-apos-pericia-em-favela.html; http://g1.globo.com/rio-dejaneiro/noticia/2016/03/moradores-protestam-por-morte-de-menino-rian-em-madureira-no-rio.html. 4 Link da matéria e dos comentários analisados: http://g1.globo.com/rio-dejaneiro/noticia/2016/03/moradores-protestam-por-morte-de-menino-rian-em-madureira-no-rio.html.
} 
Neste ponto, é pertinente lançar um olhar discursivo sobre o funcionamento do comentário no meio digital. Nos portais de notícias, o leitor pode assumir a posição de autor de comentários. Isso também acontece nas notícias que retratam a violência contra criança, conforme vemos no caso de Ryan e em tantos outros. Podemos observar que determinados sentidos ressoam nos comentários de internautas que, sob efeito da coerência e do encadeamento, expressam "livremente" suas opiniões na rede eletrônica (ilusão de origem do dizer), sendo que esses comentários são autorizados no interior do discurso jornalístico, legitimados como forma de o leitor expressar o seu ponto de vista. Tomando emprestado de Foucault a definição de comentário como "dizer enfim o que estava articulado silenciosamente no texto primeiro" (FOUCAULT, 2001, p. 24 - grifos do autor), podemos dizer que o sujeito leitor se coloca em outra posição. Ou melhor,

o leitor-autor, ao produzir distintos dizeres a respeito de um texto jornalístico, que está sob o imaginário da literalidade, não se afasta deste texto primeiro, aliás, esse texto se realiza no comentário. Nesse caso, o comentário é um discurso que normatiza a circulação discursiva, na medida em que delimita as fronteiras e as possibilidades de circulação dos efeitos de sentidos em uma determinada conjuntura histórica. (OLIVEIRA, 2014, p. 70)

Com base na citação acima, o comentário funciona no sentido de colocar evidências, reafirmar ou refutar efeitos de sentido presentes no texto primeiro. A notícia, que dá margem aos comentários que constituem o nosso corpus de análise, informa aos leitores que o pai do menino está preso por tráfico de drogas, como lemos nos seguintes trechos: "O delegado explicou que, até o momento, não há informações sobre um possível ataque deliberado contra a casa do avô do menino, ou que ele tenha sido morto por ser filho de um traficante preso" e "Não tem vingança. Até porque, o pai está preso há 4 anos. Meu filho brincava na rua. Ele foi baleado aqui fora. [...], disse Thayana".

Os enunciados aqui destacados ressoam fortemente em um grande número de comentários, silenciando o fato de uma criança ter sido vítima de um tiroteio para enfatizar discursos que estabelecem uma relação estreita entre favela, violência, tráfico e determinismo social. Nos diversos comentários dessa notícia, vemos, portanto, que a criança falada por eles não é a mesma criança que tem os direitos previstos no ECA. É relevante ressaltar que dos 43 comentários presentes na página desta notícia apenas 4 lamentavam a morte do menino e a violência que há nas favelas do Rio de Janeiro; os outros 39 mostravam-se favoráveis ao ocorrido. Esse fato é significativo para pensarmos sobre os sentidos de violência e segurança pública que estão em jogo no tecido social. Retomamos aqui uma das questões apresentadas na introdução deste artigo, que ressoará ao longo das análises: como dizeres sobre violência e segurança pública são significados? Essa indagação pode ser desdobrada em outra: para quem seria a segurança pública? O público, na sua contraposição com o privado, como veremos, não é para todos, mas apenas para alguns. Desse modo, os sentidos de 'segurança pública' constituem-se em meio à contradição da própria língua em funcionamento no social.

Desses 43 comentários, recortamos três que em seu conteúdo justificavam a violência cometida. Em nosso gesto de leitura, buscando compreender os processos discursivos que estão em jogo, produzindo sentidos, destacamos enunciados que trazem sentidos de violência, sustentados por uma discursividade constituída dentro de 
determinados preceitos que, por sua vez, significariam o "cidadão de bem”. Observemos os comentários abaixo:

1. O que é também dramático, é que o pai do menino, está preso por cometer crimes de tráfico etc. Ou seja, sentiu na própria pele, o resultado da atividade criminosa. $[122(+), 3(-)]^{5}$

2. O MENINO JÁ TINHA JEITO DE BANDIDO DESDE PEQUENO INFELIZMENTE.. JÁ ESTAVA NA CARA QUE IRIA SEGUIR OS CAMINHOS DO PAI!!!!!!! [7 (+), 14 (-)]

3. Será que no passado ele também não matou um filho de alguém e ágora está pagando por isso e infelizmente morreu quem não tem nada com isso espero que isso sirva de lição para ele quando sair da cadeias $[33(+), 5(-)]^{6}$

Em um primeiro gesto de análise, observamos que os dizeres "ser filho de traficante" e "o pai está preso há quatro anos", presentes na notícia - texto primeiro ecoam fortemente nas opiniões textualizadas pelos internautas no portal de notícias, o que já marca um posicionamento do sujeito leitor-autor, sustentado na memória do texto primeiro, que, por sua vez, é entrecortado pela memória de violência na sua relação com o tráfico de drogas. Os enunciados "Ou seja, sentiu na própria pele, o resultado da atividade criminosa" (comentário 1), pelo uso do conectivo ou seja produz um efeito de conclusão, "já estava na cara que ia seguir os caminhos do pai" (comentário 2), com o uso do advérbio já produz um efeito de certeza, e "será que no passado ele não matou o filho de alguém” (comentário 3), formulada pelo uso da expressão hipotética será que, falam sobre a morte de uma criança por bala perdida a partir daquilo que é posto como sendo a atividade de seu pai: era traficante. Há, nesses enunciados, um dizer sustentado por um imaginário que estabelece uma relação sinonímica que recobre os termos traficante e assassino. Nessa relação de sinonímia, as expressões "sentiu na própria pele"; "espero que isso sirva de lição", destacadas dos comentários 1 e 3, juntamente com o efeito de conclusão produzido no comentário 1, significam a questão da morte do filho como uma lição, um castigo para o outro que, sendo traficante7, já deve ter matado alguém, o que nos remete à memória da Lei de Talião: "Olho por olho, dente por dente".

As expressões destacadas acima, ao trazer o discurso do castigo/lição que é merecida pelo pai, produzem um discurso que se configura no batimento entre a justiça e a vingança, com o qual muitos sujeitos se identificam. Nesses comentários, portanto, são postos em oposição o imaginário do "cidadão de bem", que merece ser protegido, e o de "traficante", que deve sofrer as consequências de seus atos violentos "na mesma moeda". Esses imaginários são inscritos por uma memória que dá corpo à contradição no discurso sobre a violência presente nesses comentários: a morte de um menino é significada como castigo ao pai, como um ato de justiça e não como violência.

\footnotetext{
5 O número acompanhado pelo sinal positivo (+) representa o número de pessoas que aprovaram o comentário. O número acompanhado pelo símbolo negativo (-) representa o número de pessoas que desaprovaram o comentário.

${ }^{6}$ Transcrevemos os comentários conforme aparecem na página de notícias do G1, porém os negritos são nossos.

${ }^{7}$ Observamos o funcionamento de um imaginário social que tende a fazer uma estreita relação entre tráfico de drogas e assassinatos. Agradecemos a Rogério Modesto por nos ter chamado atenção a isso na leitura atenciosa deste artigo.
} 


\section{Retomemos o comentário 2: O MENINO JÁ TINHA JEITO DE BANDIDO DESDE PEQUENO INFELIZMENTE. JÁ ESTAVA NA CARA QUE IRIA SEGUIR OS CAMINHOS DO PAI!!!!!!!}

Chama-nos a atenção o enunciado "jeito de bandido". A expressão, formulada a partir de feições do corpo do menino Ryan, faz trabalhar uma memória de que ser negro e pobre é o mesmo que ser bandido. Essa relação sinonímica, em conjunto com o enunciado "Já estava na cara que iria seguir os caminhos do pai", dá força ao grito do "cidadão de bem", materializado pelo texto em caixa-alta ${ }^{8}$ e sustentado por préconstruídos deterministas de infância desvalida e incorrigível - atrelados a um discurso preconceituoso que considera crianças e adolescentes negros e pobres como aptos à vida no crime. Segundo Pêcheux (1988), a fundamental característica do funcionamento do pré-construído (PÊCHEUX, 1988, p. 102) é a separação entre o pensamento e o objeto do pensamento, com a pré-existência deste último. O pré-construído corresponde ao sempre-já da interpelação ideológica, que impõe a realidade e seu sentido sob a forma da universalidade, naturalizando, desse modo, um discurso violento sobre atos de violência cometido contra uma criança, conforme observamos nas análises. Nesse processo de naturalização, "o que é dito no comentário não é estranho e não rompe com o que é considerado aceitável de ser dito" (OLIVEIRA, 2014, p. 70).

A identificação do autor-leitor/comentarista com os comentários é marcada pela grande quantidade de "avaliações positivas", identificadas nos comentários pelo sinal (+), que apontam para uma possível aceitação, ou melhor, naturalização desse discurso de violência contra crianças e adolescentes pobres, negros, residentes de comunidades periféricas em grandes centros urbanos. Os comentários, na relação com outros dizeres, estão inscritos em "locais que já foram autorizados, previamente lidos e acomodados" (ROMÃO, 2006, p. 307), o que (re)produz alguns sentidos de violência, excluindo o direito à vida da criança, reforçando, assim, a própria violência. Esquece-se que a violência se dá de diversas formas, inclusive desejando ou dizendo que a morte de uma criança por bala perdida foi algo "certo" ou "justo", por ter sido consequência "das atividades criminosas" do pai. Esse seria, provavelmente, um dos modos de compreender a justiça e a segurança pública, uma vez que a violência instituída, nos comentários analisados, traz uma memória daqueles que merecem ter segurança e daqueles que devem ser deixados à mercê da violência, seja ela por parte dos policiais, do Estado ou dos traficantes.

A partir das análises dos comentários publicados nos portais de notícias, considerou-se uma distinção na constituição dos efeitos de sentidos e dos sujeitos. Observou-se que os comentários sobre outros comentários foram possibilitados pela quase simultaneidade do dizer que marca as publicações na rede eletrônica. Assim, devese levar em conta as condições de produção do discurso nas quais a internet permite outras

\footnotetext{
${ }^{8} \mathrm{O}$ texto em caixa-alta, em âmbito de mídias digitais, pode-se apresentar como um grito.

${ }^{9}$ Para Oliveira (2014), analisar a avaliação dos comentários dos internautas deve ocorrer sob o prisma do processo de constituição ideológica dos dizeres, porém deslocado das restrições e das cláusulas cominadas, pois, ao avaliar os comentários dos outros leitores-autores, o internauta não necessita aceitar os termos impostos pela página do portal de notícias. Podendo "se expressar" apenas com um clique, o seu dizer não é explicitado no site, mas seu posicionamento, sim. O leitor-autor, nesse caso, é apenas um número na quantificação das avaliações dos comentários já postados, porém, mesmo enquanto número, não deixa de produzir efeitos de sentidos sobre o tema (OLIVEIRA, 2014, p. 75).
} 
formas e possibilidades de comentar e, concomitantemente, outros modos pelos quais pode resultar a constituição do sujeito enquanto leitor-autor. Segundo Romão,

[...] na rede eletrônica, o sujeito-navegador manifesta-se a partir da voz do(s) outro(s), reclamando a teia heterogenia dos ditos alheios para fazer girar a sua condição de enunciador. Assim, a autoria é marcada por vozes que vão se apoiando em superfícies patinadas por outras vozes (sem as quais a navegação e a inscrição de sentidos ficam comprometidas), de modo a desenhar uma estranha cartografia de fragmentações de ditos, de retalhos de formulações e de retomadas de relatos, enrolados no pergaminho digital. (ROMÃO, 2006, p. 326)

Assim, nesse processo de constituição dos comentários, entrelaçados e sustentados por outras vozes - do texto primeiro ou de outros comentários - produzemse enunciados que circulam socialmente e apontam para outra forma de constituição dos laços sociais, apagando (ou tentando apagar) os vínculos do sujeito negro, pobre e morador de comunidade com a história. Seriam considerados como "sujeitos descartáveis" ou que "que devem morrer para se fazer justiça". Sujeitos simbolizados unicamente na e pela violência, postos à margem da sociedade, e, dessa forma, poderiam ser extintos de qualquer forma. Segundo Orlandi (2009, p. 227), "a segregação tem um sentido mais forte: segregado é aquele que não tem direito de existir. É o sujeito à extinção".

A extinção desses sujeitos, seja como um castigo ou como uma "prevenção", como observamos, funcionaria como uma forma de "segurança pública". Não se fala, por exemplo, em segurança pública como forma de garantia dos direitos dos moradores de comunidades; isso é silenciado. Tudo parece indicar uma retomada na memória discursiva em que o discurso da eugenia (tomado do século XIX) faz ressoar sentidos de "limpeza da sociedade". Sendo assim, um caminho de combate à violência urbana ${ }^{10}$, para manterse a segurança dos "homens e mulheres de bem" se daria pelo extermínio, ou melhor, a violência seria autorizada para o extermínio de futuros sujeitos supostamente criminosos - em sua "essência" -, como compreendemos nos dizeres do comentário 2, ou como uma forma de lição para aquele que comete crimes, observada nos comentários 1 e 3. Nesse funcionamento, a criança morta não é significada como inocente, mas como um possível vir-a-ser criminoso, e seu extermínio valeria por uma lição a ser aprendida. É nesse modo de falar sobre essa morte e de tantas outras que se constitui um discurso violento sobre a violência que foi, parcialmente, posto à tona, como veremos no(s) funcionamento(s) discursivo(s) que se entrecruzam nos dizeres materializados no texto ECA do B.

\footnotetext{
${ }^{10}$ Medeiros (2011) analisa os efeitos da adjetivação "urbana" para a qualificação do substantivo "violência" na agenda midiática atual. A autora aponta para alguns desses efeitos: o silenciamento de outros sentidos (por exemplo, "violência policial") e a naturalização do significante "violência": "trata-se de uma violência comum, inerente às cidades e comum à nossa contemporaneidade" (MEDEIROS, 2011, p. 206).
} 


\section{O ECA e o ECA do B: efeito metafórico?}

Por que o ECA do B? Qual(is) funcionamento(s) discursivo(s) estão em jogo nesse texto que se configura como uma paródia ${ }^{11}$ do ECA? Em um primeiro gesto de leitura, na tentativa de dar visibilidade à opacidade constitutiva da linguagem, formulamos um jogo metafórico (PÊCHEUX, 1997), lançando mão de algumas paráfrases. No cinema, expressão como filme B estaria atrelada a filmes com orçamentos reduzidos, atores desconhecidos, que carregariam um efeito de menor, de desprestígio. Nas fitas cassetes, havia o lado A e o lado B, que possibilitavam gravações em ambos os lados. Em relação ao mundo empresarial, o sistema B estaria atrelado a empresas que pretendem utilizar seu poder de mercado para solucionar algum tema social e ambiental. Na expressão do B, como do balacobaco - muito bom, excepcional-; ou ainda do balacobaco, uma vez que subverte, pelo deboche, as orientações do ECA, conforme observaremos nas análises. Mas a expressão "do B" também nos remete ao que não é oficial, mas que ainda subsiste em nossa sociedade. Exatamente o equívoco na designação que nos faz trabalhar na contramão dos sentidos estabilizados: pode ser x, ou y, ou z ou w... Há uma historicidade que trabalha o efeito metafórico, assim como só há deslizamento de sentidos porque os sujeitos significam dentro de uma memória. Pensar o ECA do B como um efeito metafórico é considerar a possibilidade de deslocamentos de sentido: o ECA do balacobaco, o ECA do lado B, o ECA não oficial: o lado B da questão.

E no interior do jogo metafórico, podemos observar que o deboche produzido nessa textualidade pode ser considerado o lugar de "esgarçamento da ideologia". Ou como Pêcheux nos propõe "a interpelação ideológica como ritual supõe reconhecer que não há ritual sem falhas" (PÊCHEUX, 1988, p. 300-301), ou seja, as práticas discursivas, materialmente textualizadas, são práticas ideológicas reguladas por rituais sujeitos a falhas. Se, para Pêcheux (1988), os chistes são como um sintoma da resistência ao assujeitamento ideológico ${ }^{12}$, podemos considerar que o deboche também é um sintoma da resistência, que coloca "em xeque a ideologia dominante tirando partido de seu desequilíbrio" (PÊCHEUX, 1988, p. 301). A publicação do "ECA do B" mostra que a "aceitação", por parte da sociedade, do Estatuto da Criança e do Adolescente não ocorre tão bem assim. Ainda podemos sopesá-lo como local de contradição e de diferentes reações ao equívoco, aqui entendido como "aquilo que faz com que em toda língua um segmento possa ser ao mesmo tempo ele mesmo e um outro, através da metáfora, do deslizamento, do lapso e do jogo de palavras e do duplo sentido dos efeitos discursivos" (GADET; PÊCHEUX, 2004, p. 51).

Com base nos comentários, como os apresentados na seção anterior, e nas notícias sobre casos de violência no Rio de Janeiro, deu-se a construção de um texto que funciona, sobretudo, pelo deboche constituído em uma paródia de um texto jurídico. Segundo a escritora Eliane Brum, o ECA do B

foi escrito a partir dos fatos reais ocorridos neste ano no Rio de Janeiro e de uma pesquisa sobre os comentários postados nos sites e redes

\footnotetext{
${ }^{11}$ Apesar de o texto ECA do B se configurar como uma paródia do ECA, é mais produtivo para nossas análises compreender o funcionamento do deboche, tão marcado nesse material.

${ }^{12}$ Dizer que os chistes são um sintoma da resistência do sujeito não significa dizer que o sujeito é consciente e desidentifica-se à formação discursiva na qual se insere, pois, ao fazê-lo, já se identifica a outra formação discursiva.
} 
sociais sobre esses fatos, por aqueles que se apresentavam como "cidadãos de bem" ou termos similares. Criar esse texto na primeira pessoa, juntando numa só voz os principais argumentos em circulação, foi uma tentativa de tornar esse discurso de ódio visível. Não da forma habitual, já banalizada, mas a partir do seu deslocamento para um lugar onde ele é estranho. E, assim, produzir estranhamento e incômodo. (Recortes do ECA do B)

Observamos, em uma relação de contraponto, os discursos presentes no ECA e no ECA do B:

\begin{tabular}{|c|c|}
\hline ECA & ECA do B \\
\hline $\begin{array}{l}\text { Art. } 1^{\circ} \text { Esta Lei dispõe sobre a proteção } \\
\text { integral à criança e ao adolescente. } \\
\text { [...] } \\
\text { Parágrafo único. Os direitos enunciados } \\
\text { nesta Lei aplicam-se a todas as crianças e } \\
\text { adolescentes, sem discriminação de } \\
\text { nascimento, situação familiar, idade, sexo, } \\
\text { raça, etnia ou cor, religião ou crença, } \\
\text { deficiência, condição pessoal de } \\
\text { desenvolvimento e aprendizagem, condição } \\
\text { econômica, ambiente social, região e local } \\
\text { de moradia ou outra condição que } \\
\text { diferencie as pessoas, as famílias ou a } \\
\text { comunidade em que vivem. (incluído pela } \\
\text { Lei no }{ }^{\circ} 13.257 \text {, de 2016) }\end{array}$ & $\begin{array}{l}\text { Se as crianças negras e pobres tivessem } \\
\text { aprendido a ler, não ficariam } \\
\text { interrompendo o tráfego com seus } \\
\text { corpinhos escuros. [...] Impressionante o } \\
\text { mau gosto das crianças pobres e negras, uma } \\
\text { coisa que vem de berço, mesmo, basta ver } \\
\text { como se vestem mal. Por isso, não } \\
\text { compreendem o Estatuto da Criança e do } \\
\text { Adolescente. Não a bobajada aprovada nos } \\
\text { anos } 90 \text {, por aquele monte de babacas que } \\
\text { ficam choramingando até hoje porque a } \\
\text { ditadura torturou e matou uns milhares de } \\
\text { comunistas. Matou foi pouco! Estou falando } \\
\text { do verdadeiro Estatuto da Criança e do } \\
\text { Adolescente, o que não foi feito por gente que } \\
\text { ficou desperdiçando anos estudando para } \\
\text { proteger direitos humanos de bandidinhos. } \\
\text { Como se crianças negras e pobres fossem } \\
\text { humanas! }\end{array}$ \\
\hline
\end{tabular}

Ao cotejar as duas textualidades, o documento legal e o artigo de opinião, podemos observar que o primeiro, nas suas disposições preliminares, propõe dar destaque aos direitos e proteção de crianças e adolescentes, entendidos como sujeitos em desenvolvimento, independentemente de sua condição social, conforme lemos no parágrafo único. Já o segundo, da ordem do comentário, põe em cena, por meio de seus dizeres, formas de segregações sociais que excluem crianças e adolescentes pobres e negros dos direitos e proteção garantidos pelo ECA, conforme observamos no trecho final do recorte apresentado acima: "Como se crianças negras e pobres fossem humanas". Enquanto uma textualidade fala de proteção às crianças e aos adolescentes, a outra desconstrói esses direitos no movimento de significar as mesmas como não humanas. $\mathrm{O}$ deboche, assim, estaria justamente nesse deslizamento entre as leis do ECA e as "leis" que funcionariam, de fato, para essas crianças e adolescentes moradoras de comunidades carentes. Vejamos um trecho:

Se os moleques soubessem ler e soubessem o seu lugar, estariam aí, vivos, pra ficar chapinhando no esgoto, como gostam. Como não tenho estômago pra sujeira na via pública, resolvi sistematizar a lei em vigor e fazer o manual de 2015, versão atualizada, para ver se param de 
emporcalhar o chão com seus miolos. Uma coisa bem didática, bem simples, pra que mesmo uma raça inferior consiga entender. (Recortes do ECA do B)

Seriam, portanto, dois sistemas: o lado A - a letra da lei não praticada e o lado B - a lei não escrita, porém praticada. E a principal questão entre as duas se daria em relação à interpretação (leitura) feita de cada uma. Segundo Haroche (1992), no processo de constituição do sujeito jurídico, imputa-se uma necessidade de clareza da linguagem, de banir a ambiguidade, objetivando melhorar a comunicação, fazendo-se "entender, mas não compreender" (HAROCHE, 1992, p. 84). No cerne da problemática da ambiguidade colocada como uma questão de língua está a inteligibilidade do texto legal, que se pretende compreensivo. Instaura-se uma demanda pela clareza, ou melhor, desambiguização e logicidade na relação do sujeito com a língua; uma relação que exige transparência, objetividade, literalidade. Há dois polos que se desenham: o da objetividade (caracterizada pelo rigor) disjunto do polo da subjetividade (caracterizado pela indeterminação e o inefável)" (ORLANDI, 2007, p. 14). Para a referida autora, o assujeitamento (sujeito jurídico) apoia-se no rigor, na precisão, na transparência, na letra $^{13}$, na técnica: no polo da objetividade. Estabelece, com esse assujeitamento, uma relação entre o direito e o saber: "o direito ao saber, à inteligibilidade, à curiosidade, à abertura, em resumo, todos nascidos da troca e da expansão econômica" (HAROCHE, 1992, p. 84). O polo da subjetividade marca o sujeito pela imprecisão, pelo direito à indeterminação. O sujeito-autor do ECA do B parece jogar com esses dois polos.

A seguir, inserimos mais dois recortes:

O ECA do B é a lei não escrita, mas entranhada no sistema, que rege a prática cotidiana do país.

Estou falando do ECA que vale, o das ruas, a lei na prática, mesmo. $\mathrm{O}$ outro, o oficial, é só pra botar na biblioteca daqueles intelectualoides de esquerda, pra encherem aquela boca mole de porcaria politicamente correta e se exibirem em reunião da $\mathbf{O N U}$. (Recortes do ECA do B)

Na contraposição entre o ECA e o ECA do B, constituída pela oposição entre " $a$ lei que é prática cotidiana do país", "a que vale”, "o ECA das ruas" e a "lei que é só para botar na biblioteca daqueles intelectualoides de esquerda", ou seja, a lei presente apenas no papel e não posta em prática no social, é-nos caro o conceito de juridismo (LAGAZZI, 1988), uma definição que desvela estreiteza das relações de poder interpessoais cotidianas. O jurídico corresponde, assim, à legislação concebida por uma sociedade, o que configura o sistema jurídico. Já o juridismo é compreendido como "intertextualidade da instância jurídica, do Direito" (LAGAZZI, 1988, p. 46). O juridismo está atrelado ao dizer cotidiano que implica o jurídico sem explicitá-lo, isto é, como a relação dos direitos e deveres deriva para o senso comum. Isso significa que "se mantém uma certa mobilidade (flexibilidade) entre direitos e deveres, responsabilidades, cobranças e justificativas no cotidiano. [...]. A implicitação é o ponto de sustentação da ordem cotidiana, porque é por onde o simbólico se mantém" (LAGAZZI, 1988, p. 4647), constituindo, assim, relações hierarquizadas de comando-obediência (cf. LAGAZZI, 1988). Observemos o recorte abaixo:

\footnotetext{
${ }^{13}$ Em relação à língua, pretende-se a inteligibilidade, ao menos no jurídico.
} 
Por isso, não compreendem o Estatuto da Criança e do Adolescente. Não a bobajada aprovada nos anos 90 , por aquele monte de babacas As crianças negras e pobres do Brasil só são achadas por bala perdida porque não sabem ler o verdadeiro Estatuto da Criança e do Adolescente. (Recortes do ECA do B)

Ressaltamos desse trecho o enunciado "bobajada aprovada nos anos 90" e a palavra "verdadeiro" que marcam fortemente a oposição ao outro, ao ECA (e, contiguamente, ao jurídico), mas que no cotidiano é silenciado, é apagado quando se trata de crianças e adolescentes negros e pobres. Desse modo, o adolescente e a criança do Estatuto da Criança e do Adolescente não são todos; há aqueles que ficam segregados, fora desse status, e o que lhes é garantido (ou que lhes é permitido) é o juridismo inscrito na "lei" da violência: bala perdida, bala achada, policiais violentos... E no ECA do $B$, o que vemos é um cotidiano em que o outro, o que se coloca como "cidadão do bem"14 detentor de direito e deveres, exclui essas crianças do mesmo direito.

O funcionamento do deboche parece se dar pela presença conspícua, pelo excesso, de determinados pré-construídos, jogando com a ausência da legitimidade de direitos (previstos no $\mathrm{ECA}^{15}$ ) para essas crianças, significadas tanto no ECA do B quanto no comentário 2 como bandidos, bandidinhos. O dizer, desse modo, materializa-se na tensão entre o já-dito do interdiscurso, como o que significa antes em outro lugar e retorna pelo efeito de excesso de obviedade - se a criança é negra e pobre, logo será um bandidinho, (re)inscrevendo o dizer no intradiscurso (eixo da formulação).

Continuemos o percurso analítico, lançando um olhar para alguns títulos das leis:

1) Lei Herinaldo: criança preta não pode correr na rua

2) Lei Cristian: adolescente preto não pode jogar futebol

3) Lei Jesus: criança pobre não pode ficar sentada na frente de casa (Recortes do ECA do B)

As leis do ECA do B são designadas pelos nomes das crianças, todas assassinadas em 2015. Medeiros (2011) nos lembra de que os sujeitos que sofrem violência da força policial acabam não tendo direito ao nome. Onde residiria o direito desses sujeitos ao nome próprio? Seriam mais um número nas estatísticas? Para a referida autora,

dar nome é uma obrigação perante o Estado. Se o processo de nomeação antecede o Estado e tem injunções outras de várias ordens outras (Guimarães, 2002; Medeiros, 2006), na sociedade contemporânea este passa a interferir nesse processo: se ter nome é um direito perante a lei, nomear é dever do cidadão. O nome próprio é, portanto, da ordem da lei, da instância jurídica. [...] Contudo, no embate com a violência policial, a identificação pelo nome deixa de comparecer como direito jurídico. (MEDEIROS, 2011, p. 211)

\footnotetext{
${ }^{14}$ Expressão retirada do corpus (ECA do B).

${ }^{15}$ Podemos citar, por exemplo, o artigo $5^{\circ}$ : "nenhuma criança ou adolescente será objeto de qualquer forma de negligência, discriminação, exploração, violência, crueldade e opressão, punido na forma da lei qualquer atentado, por ação ou omissão, aos seus direitos fundamentais".
} 
O ECA do B brinca, e ao mesmo tempo, indica essa contradição, reivindicando o direito do nome dessas crianças, ou melhor, o direito à existência dessas crianças que tiveram suas vidas apagadas. A nomeação dessas leis, portanto, rememoram o funcionamento de leis que recebem os nomes das vítimas que sofreram o crime sobre o qual elas tratam, como a Lei Maria da Penha. Nesse sentido, essas crianças são tratadas como vítimas, passando a ser significadas como tal ${ }^{16}$ e não mais como "futuros bandidos". O deboche produzido pelo ECA do B em relação ao ECA, no movimento de nomeação das leis, começa a dar visibilidade à crueldade que há na(s) lei(s) praticada(s) no cotidiano - no juridismo relacionado a essas crianças - , produzindo, assim, uma denúncia a esse discurso de ódio. Assim, ao mesmo tempo em que temos o apagamento das crianças e dos adolescentes pobres e negros devido à negação de seus direitos, temos os seus nomes nomeando as leis, o que, por sua vez, reforçam a existência do sujeito. Ao nomear/designar as leis com os nomes das crianças, o sujeito que estava segregado é posto em foco. Há um movimento de contradição na tessitura do discurso: um constante embate entre o silenciamento da criança e do adolescente pobre e negro e a sua evidência como sujeito nos nomes das leis.

Outro ponto que nos chama atenção é o fato de que as leis apresentadas no ECA do $B$ são marcadas pela negação: criança pobre não pode ficar sentada para fora de casa; adolescente pobre não pode brincar com celular. Não tem direito ao básico, não tem direito à segurança também. Essa negação, constante nas apresentações das leis presentes no $E C A$ do $B$, dá visibilidade a um discurso de prescrição da ordem e não de proteção, o que produz um efeito de exclusão desses sujeitos a seus direitos básicos como brincar e poder ficar na rua. Materializa-se, assim, uma tensão social, resultante desse discurso segregacionista e excludente.

Vejamos, agora, outro recorte:

Uso: a aplicação mais recente da lei número 1 do ECA do B ocorreu em 23 de Setembro de 2015. Herinaldo Vinicius Santana, de 11 anos, levou um tiro no peito, no Caju, zona portuária do Rio de Janeiro.

Uso: a aplicação conhecida mais recente da lei número 2 do ECA do B foi em 8 de Setembro de 2015. Cristian Soares Andrade, de 13 anos, foi baleado e morto na região de Manguinhos, no Rio de Janeiro.

Uso: A última aplicação conhecida da lei número 3 do ECA do $\mathrm{B}$ ocorreu em 2 de abril de 2015. Eduardo de Jesus Ferreira, de 10 anos, foi baleado na cabeça, na porta da sua casa, no conjunto de favelas do Complexo do Alemão, na zona norte do Rio de Janeiro. (Recortes do ECA do B)

Para cada lei do ECA do B, apresenta-se um uso, que promove um efeito de fechamento de cada lei nomeada. A expressão "USO:" traz um exemplo de "aplicação da lei” como forma de denúncia da violência contra esses jovens. Porém, não há apenas denúncia no uso das leis, a negação, que materializa a tensão da segregação social, e o fato de nomear as leis com os nomes dos jovens que sofreram algum tipo de violência também se constituem como marcas que denunciam ao dar visibilidade ao discurso de ódio e ao silenciamento dessa tensão. Nesse sentido, as denúncias configuradas

\footnotetext{
${ }^{16}$ Agradecemos novamente a Rogerio Modesto, por nos fazer atentar para o funcionamento da nomeação
} das leis. 
constroem um objeto de referência discursiva, que não era conhecido (PAYER, 2006, p. 64), ou era silenciado. Especificamente em nossos recortes, esse objeto de referência discursivo configura-se na relação entre dar visibilidade à violência contra crianças e jovens negros e pobres e conferir o apagamento de um discurso segregacionista a respeito desses, produzindo, assim, a textualização do conflito:

reafirma[r] o trabalho da memória discursiva na formulação dos dizeres e, consequentemente, na construção desse objeto discursivo que passa a ser conhecido. É necessário, assim, ratificar a denúncia como um gesto de linguagem que constrói e visibiliza um objeto de referência discursiva, mas não como mera visibilidade de algo nunca dito e sim como a exposição de sentidos que ao se cruzarem produzem o conflito, a tensão, o dissenso. (MODESTO, 2015, p. 172)

O conflito e a tensão estão textualizados, nessas denúncias, ao materializar, pelo deboche, a segregação, a apologia ao extermínio em prol da segurança pública dos "cidadãos de bens".

Tendemos a finalizar nosso gesto analítico com a retomada de mais um trecho do ECA do B.

Dizem que anunciar a ironia estraga a ironia. Até um tempo atrás, eu concordaria de imediato com essa afirmação. Não mais. Hoje, é preciso avisar, porque como já aconteceu com outros colunistas, há quem se identifique tanto com esse discurso que vai fazer dele uma leitura literal e acreditar que eu finalmente "vi a luz". Para essas pessoas, assim como para seus pares, o que é denúncia se converterá em defesa do ódio e do racismo e do linchamento e da execução. E assim será replicada. Não posso correr esse risco em tempos tão agudos. Usando os instrumentos da ironia e da paródia, busco denunciar quem acredita nesse discurso e o dissemina. Se você se identificou com o texto, é também você que estou denunciando. (Recortes do ECA do B)

Sob uma determinada exposição da textualização, o equívoco se mostra, faz-se marcadamente presente: "racha-se com o esperado" (MODESTO, 2015), com os sentidos estabilizados que aproximariam o sujeito a uma FD segregacionista e, concomitantemente, racista, haja vista que "o laço que constrói é contrário ao que está no ordinário do sentido" (MODESTO, 2015, p. 173). Assim como a ironia, o deboche por ser inesperado e inovador, funciona como um deslizamento que acaba por propor uma ruptura com os sentidos já sedimentados em compartimentos institucionais (como os comentários em rede eletrônica); dito de outra forma, efeitos de dissonâncias (ORLANDI, 1986) são materializados pelo modo como esses sentidos são desestabilizados. De um lado, o esforço de manter uma leitura literal, com ilusão de um texto referencial, de outro, a ressignificação, o deboche.

Em Hoje, é preciso avisar parece haver uma tentativa expressa de controle dos processos de significação, em consequência de um determinado gesto de leitura, que trabalha em dupla direção, conforme destacamos: 1) orientada para "leitura autorizada" que possibilitaria alguns encaminhamentos; 2) denúncia para aqueles que se identificam 
com os enunciados violentos, caso sejam efetivamente tomados como "literais". No confronto entre esses dois gestos de leitura possíveis, o sujeito questiona a validade dos enunciados de FDs racistas e segregacionista; dá, assim, a voz a ela para impedi-la de falar (ressoar sentidos). Rompe abertamente com os sentidos já instalados de uma FD da violência contra crianças pobres, negras e permite o movimento da denúncia, buscando desconstruir a ordem do verdadeiro daquelas formulações.

Aquilo que poderia anular os efeitos do funcionamento discursivo do deboche aponta para a denúncia. Em outros termos, em Não posso correr esse risco em tempos tão agudos desfaz o efeito potencialmente desorganizador de alguns sentidos que circulam nos comentários para promover a denúncia e, por conseguinte, dar visibilidade à tensão. Abrem-se, então, dois efeitos-leitor possíveis: supõe-se um leitor que seria aquele que reconheceria/identificaria os saberes de uma FD (posição de um leitor "bem comportado"); e outro que se desidentificaria, boicotando aqueles saberes. Isso parece ser feito pela ordem do absurdo, dos sentidos dissonantes. Por fim, em Se você se identificou com o texto, é também você que estou denunciando apresenta uma posição explícita em que "a denúncia supõe no horizonte da interlocução um sujeito representado na posição de poder tomar providências que levariam a 'reverter/modificar' o estado de coisas denunciado" (PAYER, 2006, p. 66). São gestos de resistências produzidos pelo funcionamento da denúncia, marcada pelo deboche ao ECA, ao jurídico não praticado.

\section{Algumas considerações finais}

Propomos, neste artigo, analisar materiais distintos - os comentários de notícia de jornais online e o artigo de opinião ECA do B - para compreender sentidos que circulam em nossa sociedade sobre violência e segurança pública na sua relação com crianças e adolescente. Em tais materiais, foi possível observar funcionamentos discursivos distintos, mas que entrecruzam na relação com o social. Nos comentários analisados sobre a morte do menino Ryan, a negação ao direito à segurança pública está imbricada em um discurso que significa a morte de uma criança como castigo ou como uma forma de prevenir a violência contra o "cidadão de bem". Nesse imbricamento, busca-se silenciar a tensão que há nas relações sociais configuradas em nossa sociedade, em que os pertencentes à classe dominante têm direitos e deveres, enquanto outros têm apenas deveres ou são postos à margem. Os sujeitos-autores dos comentários têm seus dizeres autorizados por outras vozes, outros dizeres, inscritos nos discursos dominantes, que buscam significar a violência como sendo apenas aquela cometida contra o "cidadão do bem". Ao negar a violência contra esses sujeitos segregados, constitui-se outra violência, que se dá na relação do simbólico com o político.

Em relação ao ECA do B, ao longo dos dizeres sobre violência, tece-se um discurso que funciona pelo deboche, tendo em conta a relação que faz circular socialmente um determinado sentido de violência, marcada fortemente nos comentários publicados na Internet. As leis do ECA do B - Lei Herinaldo: criança preta não pode correr na rua, por exemplo -, no jogo com o ECA, vão sendo construídas por um discurso de deboche em relação à violência. 
O funcionamento do deboche, nesse sentido, denuncia dizeres violentos sobre a violência e a negação dos direitos dessas crianças. Há aí outro movimento do deboche: ele não é aquele que nos leva ao riso, mas sim a outros discursos sobre a violência, sobre quais os sentidos de ser criança e o de ser adolescente em outras condições sociais, diferentes das classes dominantes. O deboche materializa a denúncia e, assim, textualiza o conflito e as tensões sociais. Com base em nossas análises, ocorre dizermos que o mecanismo de funcionamento do deboche atua, sobretudo, na base da violação de um "saber". É possível compreendê-lo, portanto, como desencadeado pela violação do saber de uma formação discursiva. No caso do ECA do B, uma violação ao saber dos direitos das crianças e dos adolescentes; violação que alguns sujeitos enunciam, como visto nos comentários sobre a morte de Ryan, e que outros denunciam, como no ECA do B, apontando para o perverso que está inscrito nos comentários, no próprio modo de se enunciar sobre a violência contra crianças e adolescentes pobres e negros, na própria significação da segurança pública.

Não esgotamos - e não tínhamos pretensão de fazê-lo - as possibilidades de análise do nosso corpus. Várias outras questões poderiam (e podem!) ser suscitadas. Tão somente apontamos um caminho entre vários que poderão ser trilhados em outras direções.

\section{Referências bibliográficas}

HAROCHE, C. Fazer dizer, querer dizer. São Paulo: Ed. Hucitec, 1992.

FOUCAULT, M. A ordem do discurso. 7ª. ed. São Paulo: Loyola, 2001.

LAGAZZI, S. O desafio de dizer não. Campinas: Pontes, 1988.

MEDEIROS, V. Posso me identificar? Mídia, violência e movimentos sociais. Em: ZANDWAISS, A.; ROMÃO, L.M.S. (Orgs.). Leituras do político. Porto Alegre: Editora da UFRGS, 2011. p. 201-219.

MODESTO, R. A denúncia na textualização do social no enlace das materialidades significantes. Línguas \& Letras, v. 16, p. 158-176, 2015.

OLIVEIRA, L.C. Comentários de leitores: a violência noticiada na internet. Em: CARMO, A.S. de A.; CATTELAN, J.C. (Orgs.). Análise de discurso: estudos de estados de corpora. Toledo, PR: Fasul, 2014.

ORLANDI, E. A casa e a rua: uma relação política e social. Em: Discurso em Análise. Sujeito, sentido, ideologia. Campinas: Pontes, 2012.

Espaço da violência: o sentido da delinquência. Cadernos de Estudos Linguísticos, UNICAMP, v. 51, p. 219-233, 2009. 
ORLANDI, E. O sujeito discursivo contemporâneo: um exemplo. Em: INDURSKY, F.; FERREIRA, M.C.L. (Orgs.). Análise do discurso no Brasil. São Carlos: Claraluz, 2007. p. 11-20.

Desorganização cotidiana. Escritos [Percursos Sociais e Sentidos nas Cidades]. Campinas, LABEURB/UNICAMP, n.1, p.3-10, 1999.

Desconstrução e construção do sentido: um estudo da ironia. Série Estudos. Faculdades Integradas de Uberaba, nº. 12, p. 66-96, 1986.

PAYER, M.O. Escrever, (d)enunciar a verdade, sugerir sentidos. Em: MARIANI, B. (Org.). A Escrita e os escritos: reflexões em Análise de Discurso e Psicanálise. São Carlos: Claraluz, 2006. p. 59-70.

PÊCHEUX, M.; GADET, F. A língua inatingível: o discurso na história da linguística. Campinas: Pontes, 2004.

PÊCHEUX, M. Semântica e discurso: uma crítica à afirmação do óbvio. Campinas. Editora da Unicamp, 1988.

Análise automática do discurso. In: GADET, F. \& HAK, T. (org.). Por uma análise automática do discurso. Campinas: Editora da Unicamp, 1997, p 61- 162.

PETRI, Verli. O funcionamento do movimento pendular próprio às análises discursivas na construção do "dispositivo experimental" da Análise de Discurso. Em: ; DIAS,

C. (Org.). Análise de Discurso em perspectiva: teoria, método e análise. Santa Maria: Editora da UFSM, 2013. p. 39-48.

ROMÃO, L.M.S. O cavalete, a tela e o branco: introdução à autoria na rede eletrônica. DELTA, São Paulo, v. 22, n. 2, p. 303-328, 2006. Disponível em <http://www.scielo.br/scielo.php?script=sci arttext\&pid=S0102$\underline{44502006000200004 \& \operatorname{lng}=\mathrm{en} \& n r m=\mathrm{iso}}>$; acesso em maio 2016.

Artigo recebido em: junho de 2016.

Aprovado e revisado em: julho de 2016.

Publicado em: agosto de 2016

\section{Para citar este texto:}

BAALBAKI, Angela Corrêa Ferreira; D'OLIVO, Fernanda Moraes. A segurança não é para todos: discursos sobre violência e segurança pública. Entremeios [Revista de Estudos do Discurso], Seção Temática [Os discursos sobre segurança em meio a políticas e processos de significação], Programa de Pós-graduação em Ciências da Linguagem (PPGCL), Universidade do Vale do Sapucaí, Pouso Alegre (MG), vol. 13, p. 247-262, jul. - dez. 2016.

DOI: http://dx.doi.org/10.20337/ISSN2179-3514revistaENTREMEIOSvol13pagina249a264 